\title{
Diversidade genética de Litopenaeus vannamei cultivado na Bahia
}

\author{
Marcelo Magalhães ${ }^{(1)}$, Romari Alejandra Martinez ${ }^{(1)}$ e Fernanda Amato Gaiotto(1)
}

(1)Universidade Estadual de Santa Cruz, Laboratório de Marcadores Moleculares, Rod. Ilhéus-Itabuna, Km 16, Salobrinho, CEP $45650-000$ Ilhéus, BA. E-mail:magalhaes_ms@yahoo.com.br, cebus@yahoo.com, gaiotto@uesc.br

\begin{abstract}
Resumo - O objetivo deste trabalho foi avaliar a variabilidade genética de estoques comerciais do camarão Litopenaeus vannamei, por meio de marcadores RAPD e diferentes métodos estatísticos de análises, em Canavieiras, BA. Vinte primers foram utilizados para a obtenção de 59 marcadores polimórficos. A análise com o programa AMOVA evidenciou diferenciação genética significativa entre os estoques, $\operatorname{com} \Phi_{\mathrm{ST}}=0,186(\mathrm{p}<0,001)$. Entretanto, as análises obtidas com o programa HICKORY sugeriram não existir estruturação $\left(\theta^{\beta}=0,002\right)$, mas considerável taxa de endogamia dentro dos estoques, em razão, provavelmente, do cruzamento entre indivíduos geneticamente mais similares $(f=0,729$ ). Testes com bootstrap mostraram 48 como o número mínimo de marcadores RAPD adequados para estudos de variabilidade genética nessa espécie. Pelo dendrograma, gerado a partir da matriz de similaridade de Jaccard $(\mathrm{Sj})$, observou-se que nos três estoques comerciais estudados existem animais geneticamente distintos.
\end{abstract}

Termos para indexação: marcadores moleculares, variabilidade genética, aqüicultura, RAPD.

\section{Genetic diversity of Litopenaeus vannamei cultivated in Bahia State, Brazil}

\begin{abstract}
The objective of this work was to evaluate the genetic variability of commercial stocks of shrimp Litopenaeus vannamei, using RAPD markers and different statistical methods of analysis in Canavieiras, BA, Brazil. Twenty primers were used to obtain 59 polymorphic markers. A significant differentiation among stocks, with $\Phi_{\mathrm{ST}}=0.186(\mathrm{p}<0.001)$, was observed by analysis with the software AMOVA. However, an analysis with the software HICKORY suggested no genetic structure $\left(\theta^{\beta}=0.002\right)$, but considerable inbreeding within stocks, possibly due to consanguineous crossings $(\mathrm{f}=0.729)$. Statistical tests with bootstrap indicated 48 as the minimum number of RAPD markers suitable for studies on genetic variability of this species. By the dendrogram produced from the Jaccard similarity matrix, it was observed that the analyzed stocks are composed of genetically different individuals.
\end{abstract}

Index terms: molecular markers, genetic variability, aquaculture, RAPD.

\section{Introdução}

O cultivo de camarão é uma atividade em plena ascensão em todo o mundo. No Brasil, apesar dos problemas enfrentados pelos carcinocultores, com relação a enfermidades que afetaram o camarão, em 2003 o país superou o Equador em produção e tornouse líder desse segmento na América Latina (Associação Brasileira dos Criadores de Camarão, 2004). A Bahia é o terceiro maior produtor de camarão em cativeiro do Brasil, e a região de Canavieiras, no Sul do Estado, possui um número significativo de fazendas de cultivo e é a que mais se destaca nessa atividade. O Litopenaeus vannamei, conhecido como camarão-branco-dopacífico, foi introduzido no Brasil no início dos anos $80 \mathrm{e}$ é, atualmente, a principal espécie de camarão marinho cultivada no país (Gonçalves et al., 2005).
Com os avanços da biologia molecular, diversos marcadores genéticos, baseados na técnica de PCR ("polymerase chain reaction"), têm sido empregados, para avaliar a estrutura genética em populações de peneídeos (Tassanakajon et al., 1997; Brooker et al., 2000; Klinbunga et al., 2001). Marcadores como o RAPD ("random amplified polymorphic DNA"), AFLP ("amplified fragment length polymorphism") e ISSR ("inter simple sequence repeat polymorphism") possuem potencial para fornecer dados sobre a variabilidade genética de populações naturais ou cativas, sem a necessidade do conhecimento prévio da sequiência-alvo (Williams et al., 1990).

A técnica de RAPD utiliza primers curtos, com seqüência arbitrária na reação de PCR. Esses marcadores são muito utilizados porque são de fácil obtenção, apresentam elevado polimorfismo e têm custo 
relativamente baixo. Entre as diversas aplicações do RAPD, estão: a obtenção de perfil genômico de indivíduos, variedades e populações, tanto animais quanto vegetais; análise da estrutura e diversidade em populações naturais e de melhoramento; construção de mapas genéticos de alta cobertura genômica; e a localização de genes de interesse econômico (Ferreira \& Grattapaglia, 1998).

O objetivo deste trabalho foi avaliar a variabilidade genética de estoques comerciais do camarão L. vannamei, por meio de marcadores RAPD e diferentes métodos estatísticos de análises, em Canavieiras, BA.

\section{Material e Métodos}

Amostras de três diferentes empresas fornecedoras de pós-larvas foram coletadas em duas fazendas de engorda, da região de Canavieiras, BA. O total de 96 animais foi coletado dos seguintes fornecedores: $\mathrm{KT}(\mathrm{N}=32), \mathrm{AL}(\mathrm{N}=32)$ e $\mathrm{EB}$ $(\mathrm{N}=32)$. Os animais foram levados vivos, em caixas de isopor com gelo, para o laboratório de marcadores moleculares da Universidade Estadual de Santa Cruz, onde amostras de tecido da musculatura abdominal foram retiradas e fixadas em tubos de $2 \mathrm{~mL}$, com $700 \mu \mathrm{L}$ de etanol absoluto, e acondicionadas em freezer a $-20^{\circ} \mathrm{C}$ para posterior extração de DNA.

O DNA genômico foi extraído de $200 \mathrm{mg}$ de tecido, tendo-se utilizado fenol:clorofórmio:álcool isoamílico (25:24:1, v/v) (Sambrook et al., 1989).

As amplificações de DNA foram realizadas em termociclador GeneAmpPCR System 9700, com volume final de reação de $13 \mu \mathrm{L}$ composto por: $1,30 \mu \mathrm{L}$ de tampão 10x (Tris $1 \mathrm{M} \mathrm{pH} 8,3, \mathrm{MgCl}_{2} 1 \mathrm{M}, \mathrm{KCl} 50 \mathrm{mM}$ ), 1,04 $\mu \mathrm{L}$ de dNTPs (dATP, dCTP, dGTP, dTTP) a 2,5 mM, 1,04 $\mu \mathrm{L}$ de BSA (albumina bovina) a 2,5 $\mathrm{mg} \mathrm{mL}^{-1}, 3 \mu \mathrm{L}$ de primer decâmero RAPD a $5 \mathrm{ng} \mu \mathrm{L}^{-1}, 3,42 \mu \mathrm{L}$ de $_{2}$ O MilliQ, $0,2 \mu \mathrm{L}$ de Taq DNA polimerase $\left(5 \mathrm{U}^{-1} \mathrm{~L}^{-1}\right)$ e $3 \mu \mathrm{L}$ de DNA genômico $\left(1,25 \mathrm{ng} \mu \mathrm{L}^{-1}\right)$. O ciclo da PCR foi constituído por 4 min a $94^{\circ} \mathrm{C}$, para desnaturação inicial de DNA, seguido de 45 ciclos de $1 \min$ a $92^{\circ} \mathrm{C}, 1,5 \min$ a $37^{\circ} \mathrm{C}$; e 2 min a $72^{\circ} \mathrm{C}$. A extensão final foi feita a $72^{\circ} \mathrm{C}$ durante 3 min.

Foram testados 39 primers RAPD, utilizados previamente para a espécie (Freitas, 2005), a partir dos quais foi feita uma seleção baseada na quantidade e qualidade de bandas polimórficas apresentadas por esses mesmos primers. Os produtos de amplificação foram separados por eletroforese, em gel de agarose $1,5 \%$ (4 horas a $86 \mathrm{~V}$ ), visualizados em coloração com brometo de etídio. As imagens foram documentadas pelo sistema Kodak EDAS 290.

O tamanho das bandas amplificadas foi verificado por meio de padrão de peso molecular de $1 \mathrm{~kb}$ como parâmetro. Matrizes binárias foram construídas de acordo com a presença ou ausência de fragmento amplificado, para cada indivíduo. Os dados obtidos foram analisados pelos programas AMOVA v1.5 (Excoffier et al., 1992) e HICKORY v1.0.4 (Holsinger et al., 2002), para avaliação da estrutura genética dos estoques comerciais, tendo-se comparado os resultados gerados por esses diferentes aplicativos.

As análises estatísticas como o coeficiente de similaridade de Jaccard $(\mathrm{Sj})$ foram realizadas com o programa PAST v1.34 (Hammer et al., 2001), e um dendrograma foi construído com base no método de agrupamento UPGMA ("unweighted pair-group method with arithmetic averages"). A consistência entre os valores da matriz de similaridade e o dendrograma gerado foi avaliada pelo coeficiente de correlação cofenética (r), obtido por meio do programa NTSYS v1.7 (Rohlf, 1992).

Para o estabelecimento do número mínimo de marcadores RAPD, capaz de fornecer informações estatisticamente confiáveis em estudos de diversidade genética dessa espécie, foram feitas amostragens com reposição de números crescentes de locos RAPD (3, $6,9,12,15,18,21,24,27,30,33,36,39,42,45,48$, $51,54,57$ e 59), a partir das matrizes binárias. Para cada conjunto de dados, os valores de $\Phi_{\mathrm{ST}}$ foram calculados com o programa AMOVA. Para verificar a dispersão dos valores de $\Phi_{\mathrm{ST}}$, em relação à média, foi feito o cálculo do coeficiente de variação, a partir da estabilização desses valores.

\section{Resultados e Discussão}

Dos 39 primers testados, 20 foram selecionados, tendo-se obtido, ao final, um total de 59 locos polimórficos que apresentaram ótimo padrão de amplificação (Figura 1). O primer OPA09 produziu o maior número de bandas polimórficas (cinco), enquanto os primers OPP01, OPP17 e OPP19 amplificaram somente um fragmento polimórfico (Tabela 1). Os fragmentos amplificados variaram de 150 a 2.100 pares de bases (pb). Apesar de alguns 
estudos demonstrarem que para uma boa reprodutibilidade da reação de RAPD, os fragmentos amplificados devam ter extensão entre 200 e 1.500 pb (Fowler et al., 1998), os marcadores utilizados no presente trabalho apresentaram boa reprodutibilidade, observada por padrões de amplificação semelhantes em diferentes reações de PCR, nos três estoques estudados.

A variabilidade genética entre os estoques comerciais de L. vannamei, pela análise de variância molecular com o programa AMOVA, foi de 18,6\%, e a variabilidade dentro desses estoques foi de $81,4 \%$. O valor do $\Phi_{\mathrm{ST}}$, estatística análoga ao $\mathrm{F}_{\mathrm{ST}}$ de Wright (1951), encontrado no presente trabalho $(0,186)$, indica haver significativa diferenciação entre os estoques comercializados, e esse efeito poderia ser causado pela estruturação genética dos próprios estoques. Os dados gerados pela AMOVA evidenciam que os conjuntos gênicos dos estoques, fornecidos pelas empresas atuantes em Canavieiras, são substancialmente diferentes entre si. Assim, tais animais podem apresentar respostas diferenciadas às mudanças drásticas das condições ambientais, introdução de um potencial agente patogênico e desempenhos contrastantes diante de uma determinada fórmula de ração ou método de manejo (De Donato et al., 2005).

Os valores de $\theta^{\beta}$, um estimador das estatísticas F $_{\text {ST }}$ de Wright (1951), obtidos com o programa HICKORY, apresentaram-se estáveis diante dos modelos analisáveis, tendo variado de 0,001 a 0,012. Como modelo estatístico mais adequado para as análises, o DIC ("deviance information criterion") indicou o "full model" (DIC $=887,556)$. O valor de

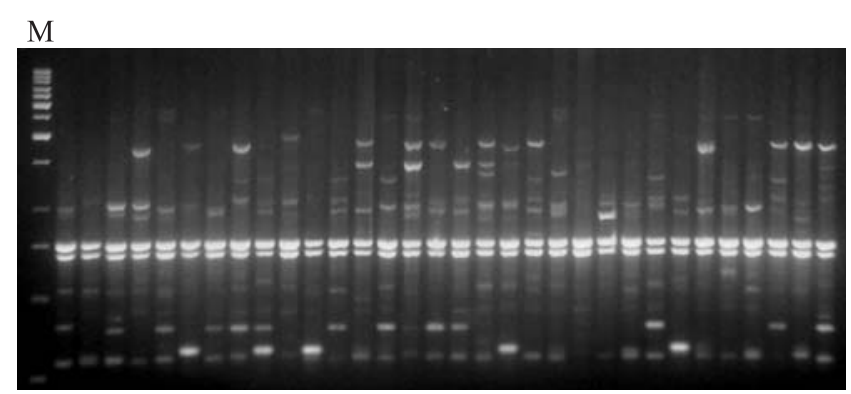

Figura 1. Padrão de bandas RAPD, amplificadas a partir de 32 indivíduos de um estoque comercial de Litopenaeus vannamei, com uso do primer OPA10. M: marcador de peso molecular $1 \mathrm{~kb}$. $\theta^{\beta}$ observado nesse modelo foi de 0,002 (intervalo de confiança a $95 \%$ igual a $0,0003-0,0078$ ), e o índice de endogamia intrapopulacional (f) foi 0,729 (intervalo de confiança a $95 \%$ igual a $0,495-0,936$ ). Esses resultados mostram taxa relevante de endogamia, em conseqüência do cruzamento entre indivíduos consangüíneos, o que evidencia a existência de possível seleção intencional, ao longo de gerações seguidas (Freitas \& Galetti Júnior, 2002). Segundo Preston \& Clifford (2002), os processos de domesticação e melhoramento genético de espécies têm por finalidade a fixação de características desejáveis, sob o ponto de vista produtivo. Contudo, alguns estudos mostram que a perda de variabilidade genética, provocada por esses processos, pode ter efeitos negativos na produção e, por esse motivo, o monitoramento da variabilidade genética dos estoques é importante para o sucesso do cultivo de camarão (Sbordoni et al., 1986; Wolfus et al., 1997).

Comparando-se os dados gerados pelos programas AMOVA e HICKORY, verificou-se que os resultados, pelos diferentes métodos de análises, apontaram distintas causas para explicar os índices de endogamia encontrados. O método de análise de variância molecular (AMOVA), baseado na matriz de distância euclideana, é consagrado e amplamente utilizado pela

Tabela 1. Caracterização dos primers RAPD, selecionados para as análises da variabilidade genética dos estoques comerciais de Litopenaeus vannamei, na região de Canavieiras, BA.

\begin{tabular}{llcc}
\hline Primer & Seqüência & $\begin{array}{c}\text { Número de } \\
\text { marcadores } \\
\text { polimórficos }\end{array}$ & $\begin{array}{c}\text { Amplitude de tamanho } \\
\text { dos fragmentos } \\
(\mathrm{pb})\end{array}$ \\
\hline OPA02 & TGCCGAGCTG & 2 & $150-600$ \\
OPA03 & AGTCAGCCAC & 2 & $650-800$ \\
OPA04 & AATCGGGCTG & 4 & $200-1.050$ \\
OPA07 & GAAACGGGTG & 3 & $450-1.600$ \\
OPA09 & GGGTAACGCC & 5 & $320-1.600$ \\
OPA10 & GTGATCGCAG & 3 & $350-750$ \\
OPA11 & CAATCGCCGT & 5 & $450-1.100$ \\
OPA14 & TCTGTGCTCG & 2 & $750-850$ \\
OPA18 & AGGTGACCGT & 3 & $550-750$ \\
OPA20 & GTTGCGATCC & 4 & $600-2.100$ \\
OPP01 & GTAGCACTCC & 1 & 600 \\
OPP05 & CCCCGGTAAC & 4 & $400-1.050$ \\
OPP08 & ACATCGCCCA & 4 & $750-900$ \\
OPP09 & GTGGTCCGCA & 4 & $650-1.750$ \\
OPP11 & AACGCGTCGG & 3 & $450-1.400$ \\
OPP13 & GGAGTGCCTC & 3 & $650-950$ \\
OPP14 & CCAGCCGAAC & 3 & $750-1.100$ \\
OPP16 & CCAAGCTGCC & 2 & $1.300-1.400$ \\
OPP17 & TGACCCGCCT & 1 & 1.200 \\
OPP19 & GGGAAGGACA & 1 & 300 \\
\hline
\end{tabular}


comunidade científica, para realizar inferências sobre genética populacional a partir de dados dominantes (Klinbunga et al., 2001; Tremetsberger et al., 2003; Oliveira, 2005). Entretanto, com os avanços tecnológicos na área de genética biométrica, novos métodos de análises de dados obtidos por meio de marcadores dominantes têm sido desenvolvidos, para tentar solucionar algumas limitações encontradas na AMOVA, como por exemplo, a estimação de freqüências alélicas. O programa HICKORY foi idealizado para suprir essas deficiências, porém, alguns testes ainda são necessários para a validação do método utilizado por esse programa.

Alguns estudos recentes vêm comparando os resultados obtidos pelo HICKORY com os dados gerados pelo AMOVA, em diferentes espécies, e tem-se verificado, ao final, certa coerência entre esses aplicativos (Juan et al., 2004; Baus et al., 2005; Sica et al., 2005). Todavia, no presente trabalho, os resultados encontrados com o HICKORY não foram congruentes com os dados gerados pelo AMOVA. Assim, as informações geradas pelos modelos estatísticos do HICKORY devem ser utilizadas com cautela. Talvez, um dos motivos da incongruência entre esses resultados se deva à utilização de diferentes formas de estimação do $\mathrm{F}_{\mathrm{ST}}$ por esses programas (Cockerham, 1969; Excoffier et al., 1992). Embora Holsinger et al. (2002) tenham demonstrado a possibilidade da obtenção de boas estimativas de $\theta^{\beta} \operatorname{com} o$ HICKORY, eles também alertam que os índices de f, gerados com esse programa, podem ser pouco informativos. Estudos com outros modelos populacionais, com essas mesmas ferramentas, são necessários para confirmar a eficiência do método utilizado pelo programa HICKORY.

Os valores de $\Phi_{\text {ST }}$ (AMOVA), obtidos com uma quantidade variada de marcadores, atingiram estabilidade (platô) a partir da utilização de 48 marcadores, o que indica que esse é o número adequado de marcadores RAPD, para a realização de inferências estatisticamente confiáveis sobre estrutura genética da espécie estudada (Figura 2). O coeficiente de variação dos valores de $\Phi_{\mathrm{ST}}$, calculado a partir da utilização de 48 marcadores, foi menor que 4\%. Segundo Gill (1987), em ciências biológicas, valores de coeficiente de variação menores que $1 \%$ são muito raros, é mais comum encontrar valores para esse coeficiente na faixa de
5 a 50\%. Telles et al. (2001) utilizaram o mesmo método do presente trabalho e determinaram 50 como o número mínimo de marcadores RAPD necessários para estimar a divergência genética entre raças bovinas.

As similaridades genéticas, medidas pelo método de Jaccard, variaram aproximadamente de 42 a $85 \%$, e o coeficiente de correlação cofenética (r) foi de 0,811 , o que indica uma boa confiabilidade do dendrograma gerado, em relação à matriz de similaridade. No dendrograma obtido, observa-se a separação de um grupo distinto, composto por 29 indivíduos oriundos do estoque comercial EB, e outro grupo mais heterogêneo, formado por indivíduos dos três estoques comerciais analisados, com predominância de indivíduos do estoque AL. Os indivíduos do estoque comercial KT encontram-se dispersos ao longo do dendrograma, o que indica que nesse estoque há um considerável nível de variabilidade genética, em relação aos demais (Figura 3). Foi possível verificar, também, que alguns indivíduos do estoque comercial KT, um indivíduo do estoque comercial EB (EB08) e um indivíduo do estoque comercial AL (AL17) apresentaram-se geneticamente mais divergentes dos demais. Esses dados mostram que nos estoques comerciais das empresas fornecedoras de pós-larvas existem animais que podem ser utilizados em processo futuro de reprodução, com o intuito de se inserir maior variabilidade genética nesses estoques, caso haja necessidade.

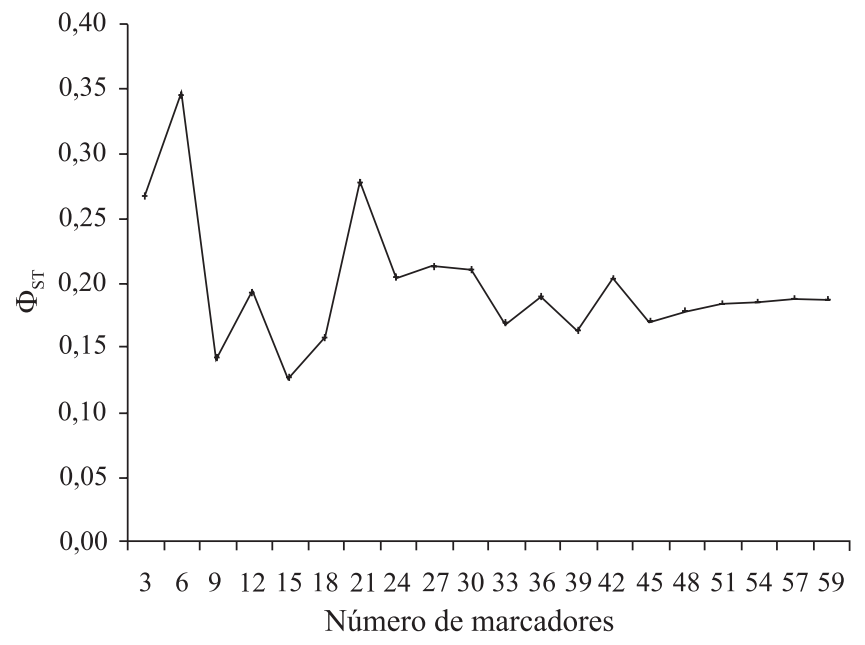

Figura 2. Variação das estimativas $\Phi_{\mathrm{ST}}$ com uso de diferentes números de marcadores RAPD. 


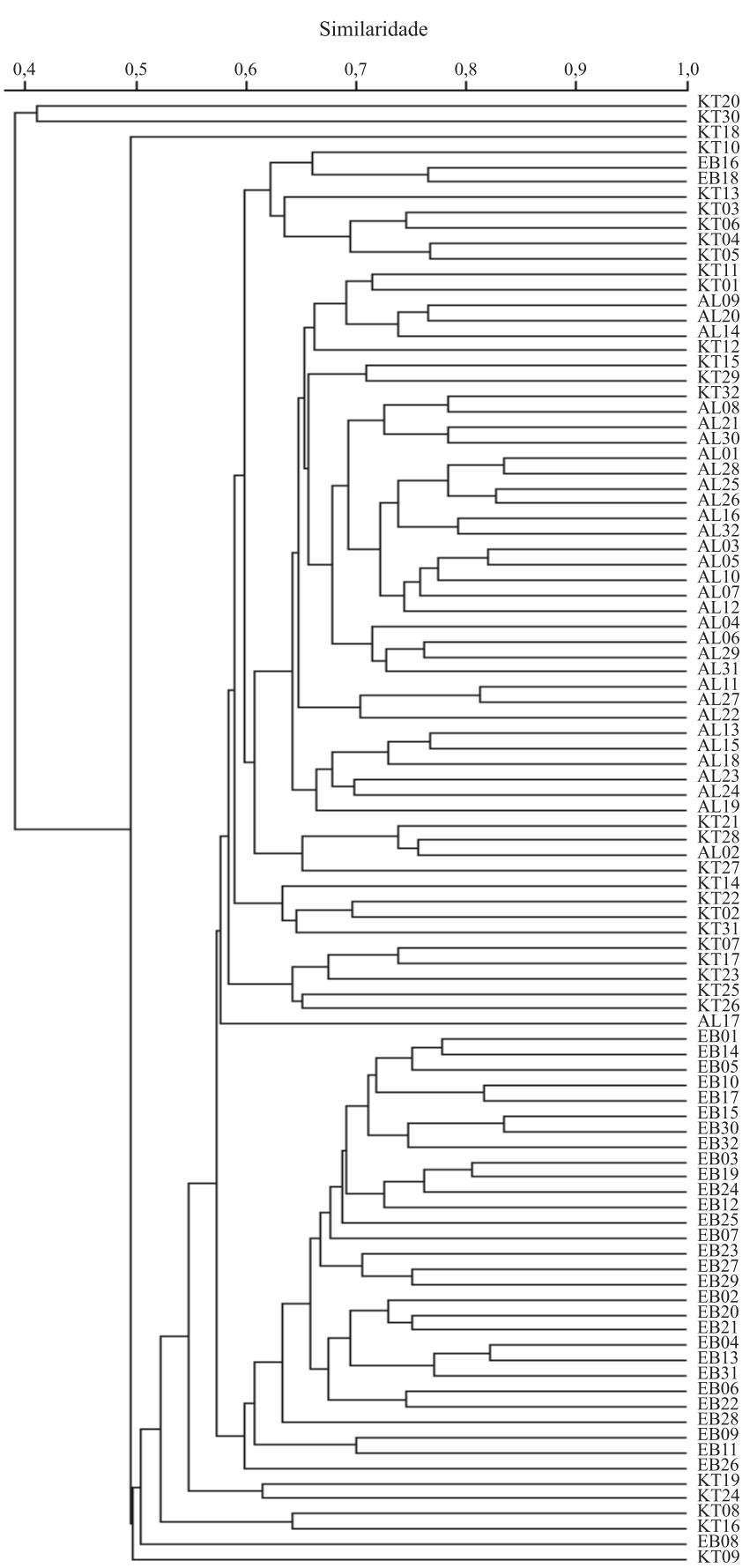

Figura 3. Dendrograma da similaridade genética, obtida entre os três estoques comerciais de Litopenaeus vannamei, definido pelo método de agrupamento UPGMA, com base nas similaridades genéticas de Jaccard calculadas a partir dos dados RAPD.

\section{Conclusões}

1. Os resultados do coeficiente de endogamia entre os estoques comerciais de Litopenaeus vannamei, obtidos pelo programa HICKORY, não são compatíveis com os dados gerados pelo AMOVA.

2. O valor de $\Phi_{\mathrm{ST}}$, gerado pelo AMOVA, mostra que os conjuntos gênicos, utilizados pelos fornecedores de pós-larvas de Litopenaeus vannamei, são diferentes entre si.

3. O comportamento das estimativas de $\Phi_{\mathrm{ST}}$ indica que 48 deve ser o número mínimo de loci RAPD a ser utilizado em trabalhos sobre a variabilidade genética de populações desta espécie.

4. Existe considerável variabilidade genética dentro dos estoques de Litopenaeus vannamei comercializados em Canavieiras, BA.

\section{Agradecimentos}

Às fazendas Ocean e Maricanes, pelo fornecimento dos animais; à Fundação de Amparo à Pesquisa do Estado da Bahia (Fapesb) e à Capes, pelo apoio financeiro; ao professor Luís Gustavo Tavares Braga, pela coordenação do projeto multidisplinar do qual esta pesquisa fez parte.

\section{Referências}

ASSOCIAÇÃO BRASILEIRA DOS CRIADORES DE CAMARÃO - ABCC. Projeto executivo para apoio político ao desenvolvimento do camarão marinho cultivado. Recife: ABCC, 2004. 11p.

BAUS, E.; DARROCK, D.J.; BRUFORD, M.W. Gene-flow patterns in Atlantic and Mediterranean populations of the Lusitanian sea star Asterina gibbosa. Molecular Ecology, v.14, p.3373-3382, 2005.

BROOKER, A.L.; BENZIE, J.A.H.; BLAIR, D.; VERSINI, J.J. Population structure of the giant tiger prawn Penaeus monodon in Australian waters, determined using microsatellite markers. Marine Biology, v.136, p.149-157, 2000.

COCKERHAM, C.C. Variance of gene frequencies. Evolution, v.23, p.72-84, 1969.

DE DONATO, M.; MANRIQUE, R.; RAMIREZ, R.; MAYER, L.; HOWELL, C. Mass selection and inbreeding effects on a cultivated strain of Penaeus (Litopenaeus) vannamei in Venezuela. Aquaculture, v.247, p.159-167, 2005.

EXCOFFIER, L.; SMOUSE, P.E.; QUATTRO, J.M. Analysis of molecular variance inferred from metric distances among DNA haplotypes: application to human mitochondrial DNA restriction data. Genetics, v.131, p.479-491, 1992.

FERREIRA, M.E.; GRATTAPAGLIA, D. Introdução ao uso de marcadores moleculares em análise genética. 3.ed. Brasília: Embrapa, 1998. 220p. 
FOWLER, E.V.; HOLBEN, B.A.; SHERWIN, W.B.; HOEBEN, P.; TIMMS, P. Genetic variation in captive koalas (Phascolarctos cinereus): parentage determination and individual identification. Biochemical Genetics, v.36, p.193-206, 1998.

FREITAS, P.D. Estudos de diversidade genética em camarões utilizando marcadores moleculares: manual prático. São Carlos: UFSCAR, 2005. 36p.

FREITAS, P.D.; GALETTI JUNIOR, P.M. PCR-based VNTR core sequence analysis for inferring genetic diversity of cultured prawn Litopenaeus vannamei. Genetics and Molecular Biology, v.25, p.431-434, 2002.

GILL, J.L. Design and analysis of experiments in the animal and medical sciences. Ames: The Iowa State University Press, 1987. v.1, 411p.

GONÇALVES, M.M.; LEMOS, M.V.F.; GALETTI JUNIOR, P.M.; FREITAS, P.D.; FURTADO NETO, M.A.A. Fluorescent amplified fragment length polymorphism (fAFLP) analyses and genetic diversity in Litopenaeus vannamei (Peneidae). Genetics and Molecular Biology, v.28, p.267-270, 2005.

HAMMER, O.; HARPER, D.A.T.; RYAN, P.D. Past: paleontological statistics software package for education and data analysis. Paleontologia Electronica, v.4, p.1-9, 2001.

HOLSINGER, K.E.; LEWIS, P.O.; DEY, D.K. A Bayesian approach to inferring population structure from dominant markers. Molecular Ecology, v.11, p.1157-1164, 2002.

JUAN, A.; CRESPO, M.B.; COWAN, R.S.; LEXER, C.; FAY, M.F. Patterns of variability and gene flow in Medicago citrina, an endangered endemic of islands in the western Mediterranean, as revealed by amplified fragment length polymorphism (AFLP). Molecular Ecology, v.13. p.2679-2690, 2004.

KLINBUNGA, S.; SILUDJAI, D.; WUDTHIJINDA, W.; TASSANAKAJON, A.; JARAYABHAND, P.; MENASVETA, P. Genetic heterogeneity of the giant tiger shrimp (Penaeus monodon) in Thailand revealed by RAPD and mitochondrial DNA RFLP analyses. Marine Biotechnology, v.3, p.428-438, 2001.

OLIVEIRA, C.G. Diversidade genética do ouriço-preto (Chaetomys subspinosus, OLFERS 1818 Rodentia: Erethizontidae) para auxiliar na elaboração de seu plano de manejo. 2005. 59p. Dissertação (Mestrado) - Universidade Estadual de Santa Cruz, Ilhéus.
PRESTON, N.P.; CLIFFORD, H.C. Genetic improvement of farmed shrimp: summary and implications of a global survey. Global Aquaculture Advocate, v.5, p.48-50, 2002.

ROHLF, F.L.J. NTSYS-PC: Numerical taxonomy and multivariate analysis system, version 1.7. New York: Exeter Publishing, 1992.

SAMBROOK, J.; FRITSCH, E.F.; MANIATIS, T. Molecular cloning: a laboratory manual. $2^{\text {nd }}$ ed. New York: Cold Spring Harbor Laboratory Press, Cold Spring Harbor, 1989. 540p.

SBORDONI, V.; DE MATTHAEIS, E.; COBOLLI-SBORDONI, M.; LA ROSA, G.; MATTOCCIA, M. Bottleneck effects and the depression of genetic variability in hatchery stocks of Penaeus japonicus (Crustacea, Decapoda). Aquaculture, v.57, p.239-251, 1986.

SICA, M.; GAMBA, G.; MONTIERI, S.; GAUDIO, L.; ACETO, S. ISSR markers show differentiation among Italian populations of Asparagus acutifolius L. BMC Genetics, v.6, p.17-24. 2005.

TASSANAKAJON, A.; SIRIPORN, P.; RIMPHANITCHAYAKIT, V. Random amplified polymorphic DNA (RAPD) markers for determination of genetic variation in wild populations of the black tiger prawn (Penaeus monodon) in Thailand. Molecular Marine Biology and Biotechnology, v.6, p.110-115, 1997.

TELLES, M.P.C. Marcadores RAPD na análise de divergência genética entre raças de bovinos e número de loci necessários para a estabilidade da divergência estimada. Ciência Animal Brasileira, v.2, p.87-95, 2001.

TREMETSBERGER, K.; STUESSY, T.F.; SAMUEL, R.M.; BAEZA, C.M.; FAY, M.F. Genetics of colonization in Hypochaeris tenuifolia (Asteracea, Lactuceae) on Volcán Lonquimay, Chile. Molecular Ecology, v.12, p.2649-2659, 2003.

WILLIAMS, J.G.K.; KUBELIK, A.R.; LIVAK, K.J.; RAFALSKI, J.A.; TINGEY, S.V. DNA polymorphisms amplified by arbitrary primers are useful as genetic markers. Nucleic Acids Research, v.18, p.6531-6535, 1990.

WOLFUS, G.M.; GARCIA, D.K.; ALCIVAR-WARREN, A.A. Application of the microsatellite technique for analyzing genetic diversity in shrimp breeding programs. Aquaculture, v.152, p.3547, 1997.

WRIGHT, S. The genetical structure of populations. Annals of Eugenics, v.15, p.323-354, 1951.

Recebido em 27 de março de 2007 e aprovado em 5 de julho de 2007 